\title{
Comparative study of Physical Properties on Conventional and Modified Binder
}

\author{
Apoorva Dwivedi, Prachi Kushwaha, Anirudh Mathur \\ Department of Civil Engineering, Swami Keshvanand Institute of Technology, Management \& Gramothan Jaipur - \\ 302017, Rajasthan (INDIA) \\ Email: apoorva.dwivedi10@gmail.com, prachi.kushwaha@skit.ac.in , anirudh.mathur@skit.ac.in \\ Received 2.09.2021, received in revised form 2.10.2021, accepted 2.10.2021 \\ doi: $10.47904 / I J S K I T .11 .2 .2021 .27-30$
}

\begin{abstract}
Most of the pavements are handling traffic load more than for what they have been designed. In addition to the seasonal variation, the pavement is subjected to temperature variation throughout the year. For pavement construction, type of material selected is based on the climatic condition of the location. The quality of binder is refined in order to enhance its performance during service life. In present scenario, use of polymer modified binder is very common to improve binder. In this study, two types of binders are used VG-30 and PMB-40. The changes in physical properties are measured by performing tests like softening point, ductility and elastic recovery on aged and un-aged sample. The testing was performed as per the codal provisions of IS 1201-1220-1978, ASTM-D 17540 and IRC: SP: 53-2010. The effect of ageing on physical properties of binder is presented in tabular form in this paper.
\end{abstract}

Keywords: Ageing, VG-30, PMB-40, Polymer modified.

\section{INTRODUCTION}

The global consumption of bitumen is around 102 million tonnes per year [1]. Out of which, $85 \%$ is used in pavement construction, $10 \%$ for roofing application and $5 \%$ as a sealant, for insulating purposes [2].

Bitumen is extensively used for flexible pavement construction. In developing countries like India flexible pavements are preferred more than the rigid pavement because of low construction cost and it can be constructed in stages. But the life cycle cost of rigid pavement is lower than the flexible pavement due to low maintenance cost and higher design life [2]. The need for high maintenance is due to the various distresses like rutting, potholes, cracking that are caused due to ageing and high traffic loads. When pavement is subjected to ageing it loses its viscoelastic property which leads to crack propagation [3]. The ageing of bitumen is of two types, short-term ageing and long-term ageing. The short-term ageing is induced at high temperature during mixing, manufacturing and placing of bitumen due to oxidation and loss of volatiles. The long-term ageing occurs during service life of flexible pavement. Ultra-violet light, environmental oxygen and atmospheric pressure are some of the reasons behind long-term ageing.

It was observed that ageing can be prevented when surface sealing, overlay and asphalt mixture have low voids [3]. The short-term ageing is simulated in laboratory by thin film oven test (TFOT) and rolling thin film oven test (RTFOT) while to replicate longterm ageing, the TFOT and RTFOT sample is further aged by Pressure aging vessel (PAV) test. The process of oxidation on field might be different from ageing in laboratory tests [3].

The pavement performance can be enhanced by using additives and polymers. The conventional bitumen can be modified by using crumb rubber, natural rubber and by using polymers like ethylene vinyl acetate (EVA), styrene-butadiene-styrene (SBS). These modifiers not only change the chemical properties of binder but also enhance the rheological and physical properties of binder. The performance of aged binder is also upgraded in addition to unaged binder [2].

\section{LITERATURE REVIEW}

Nazki et. al. [4] carried out an experimental study on binder modified with different percentage of graphene. The test like softening point storage stability, frequency sweep were carried out. At high temperature the face angle reduced and the effects of graphene were found remarkable. As per results it was concluded that rheological properties and resistance to rutting got improved on adding graphene.

Wang and Ye [5] investigated the rheological properties of base asphalt and modified binders. As per the study it was concluded that rheological properties were in good correlation with softening point and poorly correlated with penetration. Also, it was observed that physical properties like softening point, penetration, viscosity of modified binder got significantly improved on ageing.

Ali et. al. [6] illustrated the effect of crumb rubber modifier on physical and rheological properties on bitumen binder by performing various tests like dynamic shear rheometer (DSR), Brookefield viscometer, softening point and penetration test. The results showed an increase in softening point, decrease in penetration ageing ratio. Also, $G^{*} \sin (\delta)$, reduces with increase in crumb rubber content that results in higher fatigue resistance.

Pareek et. al. [7] carried out a comparative study on polymer modified bitumen (PMB) and conventional bitumen. The study showed that PMB has better resistance to ageing along with higher rutting 
resistance. Also, the elastic recovery found in PMB was significantly high, around $79 \%$.

Galooyak et. al. [8] investigated the physical and rheological properties of PMB and PMB modified with nanoclay. As per results, on adding nanoclay to PMB, storage stability of PMB significantly got improved. Also, softening point, viscosity increased and penetration decreased. Further, rheological properties test results revealed an increase in complex modulus, decrease in phase angle which leads to increased rutting resistance.

Kumar et. al. [9] investigated the impact of adding crumb rubber and ethylene vinyl acetate (EVA) as a modifier to conventional binder grades of 60/70 and $80 / 100$. The remarkable increase in rutting resistance was observed at $50^{\circ} \mathrm{C}$ on adding $3 \%$ EVA. The addition of modifiers like EVA and use of crumb rubber modified bitumen (CRMB) had a positive impact on rheological properties.

Polacco et. al. [10] investigated the effect of adding clay to the polymer modified binder asphalt. Binary and tertiary combination of asphalt/clay, clay and polymer to asphalt were prepared respectively. As per results, it can be concluded that rheological properties were significantly affected by mixing procedure.

Ruan et. al. [11] investigated the influence of longterm ageing on rheological properties of PMB. The long term ageing was performed either at $100^{\circ} \mathrm{C}$ in PAV or at $60^{\circ} \mathrm{C}$ in managed condition. The study shows an improvement in mechanical properties of polymer modified binder at high as well as low temperature. The result was significant and certain at high temperature in comparison to low temperature. The ductility of modified binder also got upgraded. $\mathrm{Lu}$ and Isacsson [3] studied the effects of ageing on chemical and rheological properties of bitumen and found that ageing has a notable impact on rheological properties and chemistry of binder. Good correlation was found between TFOT and RTFOT as somehow both ageing method had the same level of severity. Also found that on ageing styrene-butadiene-styrene modified binder, polymer arrest the development of sulfoxide. Also, the development of carbonyl and sulfoxide were temperature dependent phenomenon. And also strong correlation was found between increase in binder stiffness and carbonyl formation on ageing.

Based on the above research findings, some experiments were performed in order to determine the physical properties of selected grade of binder before and after RTFOT ageing. A comparison is carried out between physical properties of two different binders to establish the effects of RTFOT ageing on properties of binder by testing aged and unaged sample. Based on the results, performance of two different binders were evaluated.

\section{MATERIAL AND METHODS}

- Bitumen VG 30: The VG 30 grade of bitumen is used for laboratory work because of its significant traffic load bearing ability. The VG30 was essentially/extensively used for building extra heavy bitumen roads. It is widely used in producing cutback bitumen, pavement construction and insulation. Also, it was easily available in Jaipur as it is recommended by Jaipur Development Authority (JDA) for road construction.

- PMB-40: The modified binder PMB-40 is also used for testing purpose. It is manufactured by blending bitumen with superior quality SBS polymer (elastomeric) as per IRC: SP-53-2010 and IS 15462:2004.

The increased traffic load and intensity, variation in daily and seasonal temperature results in development of distress symptoms like cracking, rutting, and potholing on pavement surfaces. Certain modifiers are used to enhance properties of bitumen. Fatigue characteristics and rutting resistance is significantly improved on adding thermoplastic elastomer [12].

Benefits of Modifiers

- Less sensitive to temperature variations

- Improved bonding with aggregates.

- Improved resistance to fatigue which reduces the reflective cracks.

- High cohesiveness

- With high stiffness modulus the resistance to deformation increases.

It is recommended to be

- Used in concrete structure for water proofing.

- Used in high rainfall area

- Used for traffic noise reduction

- Heavy trafficked laws

- Airport runways

PMB - 40 is recommended for locations that are precisely in hot climatic areas, produced as per IRCSP 53-2010 [12] and IS15462-2004 [13]. The performance of conventional bitumen is satisfactory on most of the roads.

Testing- The comparative studies were performed on VG 30 and PMB 40 grade of bitumen. The physical tests as per IS 73-2006, IS 1201-1978 and IRC-SP 53-2010 were carried out to find out different properties of binder. All the tests were performed on two different binders before and after ageing to determine variation in properties of bitumen after ageing. The short - term ageing [RTFOT) is adopted to carry out the laboratory tests.

RTFOT- The sample is heated and moving film of bitumen is subjected to air and heat in an oven for 85 minutes at $165^{\circ} \mathrm{C}$. The outcome of heat and air on bitumen is obtained by performing various physical tests before and after ageing. The accurate values for this test have been evolved for mass change, viscosity at $60^{\circ} \mathrm{C}$ and ductility at $25^{\circ} \mathrm{C}$ [ASTM D2872-19] [14]. 


\section{LABORATORY INVESTIGATION AND RESULTS}

\subsection{Physical properties of un-aged bitumen binder:}

Table 1: Physical properties of un-aged binder

\begin{tabular}{|c|c|c|c|}
\hline Properties & VG-30 & PMB-40 & Code used \\
\hline $\begin{array}{c}\text { Softening } \\
\text { Point(R\&B) } \\
{ }^{\circ} \mathrm{C} \text {, minimum }\end{array}$ & $49^{\circ} \mathrm{C}$ & $60^{\circ} \mathrm{C}$ & $\begin{array}{c}\text { IS: } 1205- \\
1978\end{array}$ \\
\hline $\begin{array}{c}\text { Ductility at } \\
25^{\circ} \mathrm{C}, \mathrm{cm}\end{array}$ & $43 \mathrm{~cm}$ & $55 \mathrm{~cm}$ & $\begin{array}{c}\text { IS: } 1208- \\
1978\end{array}$ \\
\hline $\begin{array}{c}\text { Specific } \\
\text { gravity }\end{array}$ & 1.02 & 1.04 & $\begin{array}{c}\text { IS: } 1202- \\
1978\end{array}$ \\
\hline $\begin{array}{c}\text { Elastic } \\
\text { recovery }\end{array}$ & $24 \%$ & $52 \%$ & $\begin{array}{c}\text { IRC: } \mathrm{SP}: \\
53-2002\end{array}$ \\
\hline $\begin{array}{c}\text { Flash and Fire } \\
\text { point in }{ }^{\circ} \mathrm{C}\end{array}$ & $\begin{array}{c}254^{\circ} \mathrm{C} \\
280^{\circ} \mathrm{C}\end{array}$ & $\begin{array}{c}273^{\circ} \mathrm{C} \\
288^{\circ} \mathrm{C}\end{array}$ & $\begin{array}{c}\text { IS: } 1209- \\
1978\end{array}$ \\
\hline
\end{tabular}

\subsubsection{Softening point}

The value of softening point in PMB-40 is 1.22 times of the viscosity of VG-30 as viscosity increases on adding polymer. Also results in better rutting resistance.

\subsubsection{Ductility}

This is one of the important properties of bitumen. High ductility value is acceptable. In flexible pavements, due to the temperature variation and traffic load, deformation occurs. The binder with low ductility value may crack under this circumstance. The ductility value of PMB-40 is 1.28 times higher than VG-30.

\subsubsection{Specific gravity}

The specific gravity value is higher in PMB-40 due to the increase in aromatic type mineral impurities.

4.1.4 Elastic recovery

The elastic recovery test is used to determine the acceptability of modified binder for pavement construction. The test was performed as per IRC: SP: 53-2002. The value in PMB-40 was found $28 \%$ more in comparison to VG-30.

\subsubsection{Flash and Fire point}

The flash point is 1.07 times and fire point is 1.02 times higher in modified binder as compared to conventional bitumen VG-30.

\subsection{Physical properties after ageing}

Table-2: Physical properties of aged binder

\begin{tabular}{|c|c|c|c|}
\hline Properties & VG-30 & PMB-40 & Code used \\
\hline $\begin{array}{c}\text { Softening } \\
\text { Point }(\mathrm{R} \& \mathrm{~B}) \\
{ }^{\circ} \mathrm{C}, \text { minimum }\end{array}$ & $53^{\circ} \mathrm{C}$ & $64^{\circ} \mathrm{C}$ & $\begin{array}{c}\text { IS: } 1205- \\
1978\end{array}$ \\
\hline $\begin{array}{c}\text { Ductility at } 25 \\
{ }^{\circ} \mathrm{C}, \mathrm{cm}\end{array}$ & $41 \mathrm{~cm}$ & $50 \mathrm{~cm}$ & $\begin{array}{c}\text { IS: } 1208- \\
1978 \\
\end{array}$ \\
\hline $\begin{array}{c}\text { Elastic } \\
\text { recovery }\end{array}$ & $18 \%$ & $36 \%$ & $\begin{array}{l}\text { IRC: SP : } \\
53-2010\end{array}$ \\
\hline $\begin{array}{c}\text { Loss in } \\
\text { weight, in \% }\end{array}$ & 0.06 & 0.053 & $\begin{array}{c}\text { ASTM-D } \\
1754\end{array}$ \\
\hline $\begin{array}{l}\text { Flash and Fire } \\
\text { point in }{ }^{\circ} \mathrm{C}\end{array}$ & $\begin{array}{l}226^{\circ} \mathrm{C} \\
275^{\circ} \mathrm{C} \\
\end{array}$ & $\begin{array}{l}260^{\circ} \mathrm{C} \\
285^{\circ} \mathrm{C} \\
\end{array}$ & $\begin{array}{c}\text { IS:1209- } \\
1978 \\
\end{array}$ \\
\hline $\begin{array}{c}\text { Specific } \\
\text { gravity }\end{array}$ & 1.031 & 1.037 & $\begin{array}{c}\text { IS: } 1202- \\
1978\end{array}$ \\
\hline
\end{tabular}

\subsubsection{Softening point}

The softening point of VG-30 and PMB-40 after ageing becomes 1.08 and 1.06 times of unaged binder respectively. The softening point increases due to the increase in viscosity on ageing.

\subsubsection{Ductility}

On ageing, ductility of VG-30 and PMB-40 decreased to 0.05 and 0.1 of unaged binder.

4.2.3 Elastic Recovery

Elastic recovery of both binders decreases after ageing. The elastic recovery of modified binder is higher. The addition of polymer leads to improved resistance to rutting.

\subsubsection{Loss in weight}

On ageing, the weight loss is observed due to the loss of volatile fraction. As per codal provision, weight loss must be within $1 \%$.

\subsubsection{Flash and Fire point}

The flash and fire point of both the binders reduces after ageing. Even after ageing, flash and fire point of PMB-40 is 1.15 and 1.03 times of VG-30.

\subsubsection{Specific gravity}

The specific gravity of VG-30 becomes 1.01 times of unaged binder after ageing. While specific gravity of PMB-40 becomes 0.997 times of unaged binder after RTFOT ageing.
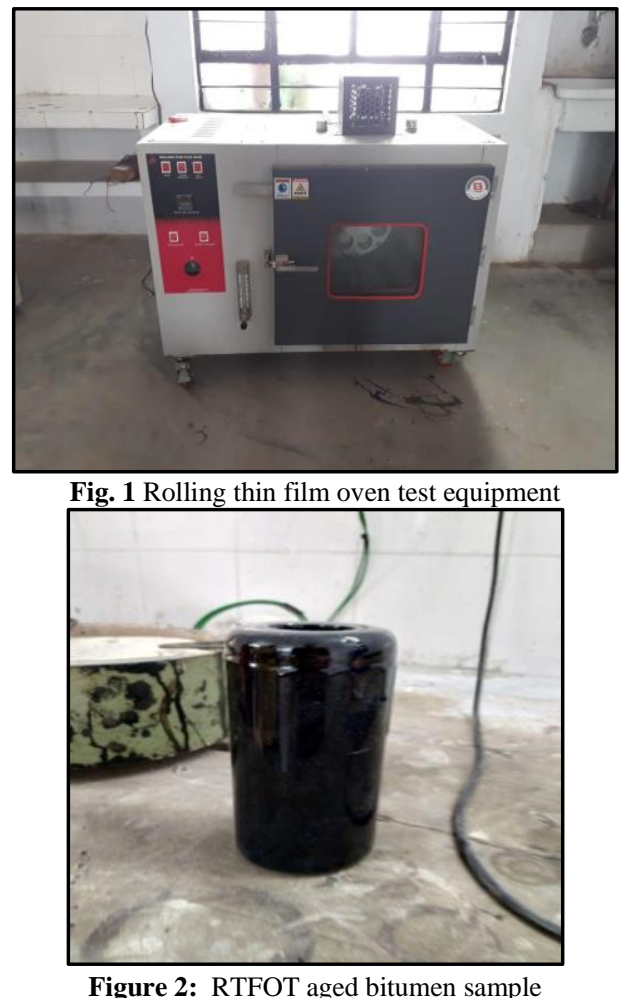

\section{CONCLUSION}

As per the results obtained, it can be concluded that bitumen exhibit physical hardness when subjected to short-term ageing by Rolling thin film oven test (RTFOT). It has been observed in both binders that after ageing, softening point increases, ductility and 
elastic recovery decreases. Also loss of weight occurs due to loss of volatile fraction. On comparing physical properties of aged and un-aged sample of PMB-40 and VG-30, it has been observed that PMB40 performed well. PMB-40 can be used in areas susceptible to high temperature and heavy traffic. It has a vast scope in the field of flexible pavement construction.

\section{ACKNOWLEDGEMENT}

This study was supported by GRV infrastructure, as the PMB-40 used for testing purpose was provided by them. The authors are thankful to them for support.

\section{REFERENCES}

[1] [1] 1. Eurobitume, A. I. (2011). The Bitumen Industry: A Global Perspective. Production, chemistry, use, specification and occupational exposure. Asphalt Institute Inc. \& European Bitumen Association-Eurobitume.

[2] Dr Robert N. Hunter, Andy Self and Professor John Read, "The Shell Bitumen Handbook", Sixth edition, ICE Publishing, London, 2015.

[3] Lu, X., \& Isacsson, U. (2002). Effect of ageing on bitumen chemistry and rheology. Construction and Building materials, 16(1), 15-22.

[4] Nazki, M. A., Chopra, T., \& Chandrappa, A. K. (2020). Rheological properties and thermal conductivity of bitumen binders modified with graphene. Construction and Building Materials, 238, 117693.

[5] Wang, Z., \& Ye, F. (2020). Experimental investigation on aging characteristics of asphalt based on rheological properties. Construction and Building Materials, 231, 117158.
[6] Ali, A. H., Mashaan, N. S., \& Karim, M. R. (2013). Investigations of physical and rheological properties of aged rubberised bitumen. Advances in Materials Science and Engineering, 2013.

[7] Pareek, A., Gupta, T., \& Sharma, R. K. (2012). Performance of polymer modified bitumen for flexible pavements. International journal of structural and civil engineering research, 1(1), 77-86.

[8] Galooyak, S. S., Dabir, B., Nazarbeygi, A. E., \& Moeini, A. (2010). Rheological properties and storage stability of bitumen/SBS/montmorillonite composites. Construction and building materials, 24(3), 300-307.

[9] Kumar, P., Mehndiratta, H. C., \& Singh, K. L. (2010). Comparative study of rheological behaviour of modified binders for high-temperature areas. Journal of Materials in Civil Engineering, 22(10), 978-984.

[10] Polacco, G., Křǐž, P., Filippi, S., Stastna, J., Biondi, D., \& Zanzotto, L. (2008). Rheological properties of asphalt/SBS/clay blends. European Polymer Journal, 44(11), 3512-3521.

[11] Ruan, Y., Davison, R. R., \& Glover, C. J. (2003). The effect of long-term oxidation on the rheological properties of polymer modified asphalts. Fuel, 82(14), 1763-1773.

[12] irc.gov.in.sp.053.2010.pdf (resource.org).

[13] gov.in.is.15462.2004 (archive.org).

[14] nazhco-33256787-RTFOT-D-2872.pdf (nazhco.com)

[15] ASTM-D1754 (https://www.astm.org/Standards/D1754)

[16] gov.in.is.1201-1220.1978 (archive.org).

\section{NOMENCLATURE}

\begin{tabular}{|l|l|}
\hline SBS & Styrene butadiene styrene \\
\hline PAV & Pressure aging vessel \\
\hline TFOT & Thin film oven test \\
\hline RTFOT & Rolling thin film oven test \\
\hline EVA & Ethylene vinyl acetate \\
\hline
\end{tabular}

